\title{
Utilization of Consultant Doctors' Competence and Impact on Perceived Psychosocial Work Environment: A Pilot Study
}

\author{
Gunnar Augustsson ${ }^{1}$, Teresia Ekelund-Book ${ }^{2}$, Bodil J. Landstad ${ }^{2,3}$ \\ ${ }^{1}$ Department of Education, Mid Sweden University, Sundsvall, Sweden \\ ${ }^{2}$ Department of Health Sciences, Mid Sweden University, Östersund, Sweden \\ ${ }^{3}$ Levanger Hospital, Nord-Trøndelag Hospital Trust, Levanger, Norway \\ Email: *gunnar.augustsson@miun.se
}

How to cite this paper: Augustsson, G., Ekelund-Book, T. and Landstad, B.J. (2017) Utilization of Consultant Doctors' Competence and Impact on Perceived Psychosocial Work Environment: A Pilot Study. Health, 9, 189-207.

http://dx.doi.org/10.4236/health.2017.91013

Received: December 20, 2016

Accepted: January 21, 2017

Published: January 24, 2017

Copyright $\odot 2017$ by authors and Scientific Research Publishing Inc. This work is licensed under the Creative Commons Attribution International License (CC BY 4.0).

http://creativecommons.org/licenses/by/4.0/

\begin{abstract}
Background: Work agencies that assign temporary jobs to doctors and nurses are becoming an increasing phenomenon. Aim: The purpose of this pilot study was to explore how consultant doctors (CDs) experience their competence as utilized in practice and what impact this has on their perceived psychosocial work environment. Methods: The findings are based on 11 interviews with CDs working on consultancy assignments in Norway. The CDs were all specialists in fields such as general practice, psychiatry, anesthesia, gynecology, orthopedics, and otolaryngology. Results: The competence that the CDs contributed to their hosting work organization was interpreted differently based on whether the consultant played an active role in the psychosocial work environment and also depended on the doctor's specialty. Not being integrated into the hosting work organization enhanced the feeling of exclusion and the idea that little or no room was available to contribute one's competence. Most of the CDs experienced their competence as being utilized to a certain extent, which strengthened their work satisfaction and feeling of playing an active role in the psychosocial work environment.
\end{abstract}

\section{Keywords}

Competence, Consultant, Doctors, Healthcare, Health Temporary

Staffing Agencies, Psychosocial Work Environment

\section{Introduction}

Previous research in health care and social services has demonstrated differences in the rules of communication and behavior in client companies' (CCs') treat- 
ment of regular staff and temporary workers [1] [2]. Augustsson [1] showed that temporary workers 1) are kept away from various contexts in which there is talk about the overall organization, 2) are kept outside more intellectually complex and decision-making contexts, 3) are associated with social outsiders, and 4) have fewer opportunities for in-house training than regular workers.

The lack of staff within the health care system is a complex and enduring problem, and a solution to the problem does not seem to continue in the foreseeable future [3]. Hiring a doctor or nurse who works for a temporary work agency (TWA) is an efficient and flexible way of dealing with a difficult situation [3].

We have chosen to use the terms "permanent employees/staff" for those working permanently at CCs and the term "consultant doctors" (CDs) or "consultants" when referring to personnel taking assignments independently or through TWAs. Consultants have the capacity to relieve ordinary staff, reduce the pressure of having too many patients, and offer competence to which the clinic normally does not have access [3].

The practice of TWAs assigning jobs is an increasing phenomenon within the Swedish and Norwegian health care systems today, and there is an ongoing debate about its expenses for the care givers. However, research into consultant medical doctors' work environments and how CCs assimilate their competences into their practices is lacking. This pilot study therefore explored how specialists in fields such as general practice, psychiatry, anesthesia, gynecology, orthopedics, and otolaryngology experience their competence as utilized in practice and what impact this has on their perceived psychosocial work environment. We plan to use the results from the exploratory pilot study as the basis for a future study based on quantitative data. The following questions are answered in this study: 1) How do consultant doctors perceive their competence to be utilized? and 2) How do consultant doctor's perceptions of the utilization of their competence impact their perceived psychosocial work environment?

\section{Research Overview}

In an ordinary workplace, the identity of the employer is clearly defined. Håkansson, Isidorsson and Strauss-Raats [4] described the triangular business relationship between the TWA, the CC and its employees, and the consultant who has been recruited for a particular mission or job. It is important to properly understand these complex relations when discussing the work environment.

Consultants are often assigned simple or standardized work tasks. Accordingly, there is a minimized integration of consultants into the CC [1] [3] [5]. In this way, permanent staff members are relieved of unattractive, simple, or standardized work tasks and acquire more advanced ones [5]. A concept of particular importance in this context is competence. Some researchers have perceived competence in terms of "earning, coordinat[ing] and integrat[ing]" [[6], p. 61]. Karlson and Fergin [7] described it "as a balance between theoretical knowledge, practical knowledge and... judgmental knowledge” (p. 5). 
Karlsson, Björklund and Jensen [8] argued that a good working environment could be the basis for healthier employees, which in turn could have a positive impact on organizational productivity. This is consistent with Håkansson, Isidorsson and Strauss-Raats [4], who argued that the psychosocial work environment needs to be understood in terms of interaction with conditions in the physical, organizational, and social environments. The consequence is that the combination of the employee's physical, organizational, and social environment seems to have sociocultural significance for the performance of work. One reason for this is that the perception of one's own psychosocial environment may be critical for one's health, welfare, and a sense of meaningful leisure [9].

Further, Jönsson [9] implied by this that a balanced psychosocial work environment offers staff "freedom to act and opportunity to influence the work" (p. 237). She also argued for a focus on the physician's psychosocial work environment in order to create "a supportive environment" (p. 242). Therefore, there is a need for explorative empirical evidence of a connection between psychosocial work factors, employee health, and production rate-not least among CDs.

The negative health consequences of a poor psychosocial work environment among employees arise from the following factors: demands, control, and social support [10]. One source of psychosocial concern among TWA employees might be the precarious working conditions and fear of being fired or not having one's contract extended [4] [11]. Not much research has been undertaken regarding the psychosocial work environment among CDs. Physicians' satisfaction with their working life depends on their access to employment, practice environments, and conditions for exercising their specialty [12].

\section{Theoretical Perspectives}

In the study, we use two perspectives for understanding and analyzing the interview material: competence and psychosocial work environment.

\subsection{Competence}

Säljö [13] stated that learning and knowledge reproduction in organizations are not isolated units but also a matter of mastering knowledge and skills in themselves. It is also a question of 'determining when a particular set of knowledge is relevant and productive and how the knowledge works in different situations' [[7], [13], p. 129, cf. [14]]. In working life, this is often referred to as competence or an individual's ability to form information, communication, learning, and knowledge to successfully identify, interpret, evaluate, and perform a certain task within a specific situation or a specific context [15]-[21]. Another important aspect of learning is the norms and values in the workplace that regulate the individual's ability to participate in various goal-oriented [22] [23] and innovative [24] activities. Therefore, competence is based on the integration between context, skills, and knowledge and may embrace both routine and expert-based tasks. As such, competence is closely related to identity and self-esteem. 


\subsection{Psychosocial Work Environment}

In work and organizational psychology, classical motivation theories suggest that work has an instrumental function, which means that work provides economical safety and satisfies material needs [25]. In addition, work contributes to the perception of personal identity, self-esteem, status, and, as in the case for many CDs, extra earnings.

One model describing psychosocial job characteristics and their relationship to health and well-being is the demand-control-support model [26] [27]. Demands refer to time pressure, mental load, and coordination responsibilities. According to Edvardsson, Larsson, and Setterlind [[28], p. 260], "an optimal stress level, when it comes to work load for instance, is achieved not when employees feel at ease in their jobs or have little to do, but rather when they feel that they have freedom to decide the pace and organization of their work" - that is, when they have high control and low demands. However, if there is no room for the consultant to contribute or no interest in his or her contribution of competence, the psychosocial work environment will be perceived as more negative.

Control comprises two components: decision authority and skill discretion. Decision authority is the ability to decide how and when a job task is to be completed. Skill discretion refers to the use of the employee's initiative and skills on the job. Experiencing an environment as affecting one's health, in which one must prove oneself while being observed, may be a challenge for CDs [9].

A third component, social support, was added to the model by Johnson and Hall [26]. Social support refers to the social climate and the possibility of receiving support from supervisors and colleagues when necessary. Such support is important because "when employees are satisfied with the quality of their relationships with coworkers... research suggests that they are also more satisfied with their overall job experience" [[29], p. 1031].

A combination of high demands, low control, and lack of social support is the worst job situation when it comes to employee health and well-being. There is strong evidence linking this job situation to cardiovascular diseases [30] [31]. A high level of control, manageable work demands, and extensive social support are crucial factors for experiencing a high level of job satisfaction and well-being [27] [32]. From this, one can assume that there is a relationship between the utilization of a CD's competence and his or her perception of the psychosocial work environment.

\section{Method}

The data collected for this pilot study were analyzed according to a phenomenological perspective because such qualitative methodological approaches tend to be based on recognition of the subjective, experiential life-world of human beings and describe their experience in depth [33].

\subsection{Subjects}

This is a small pilot study with a heterogeneous sample with regard to specializa- 
tion and geographic location. The CDs had all, at some point, been working through TWAs, so they were accustomed to entering someone else's work environment. They had many years of experience, which enabled them to be used for both routine missions and specified tasks that demanded expertise (see Table 1). Examples of expertise are the ability to operate using a specific method and the ability to anesthetizebabies. The CDs worked as consultants from three weeks a year to year-round. One of them was retired and still working as a consultant as desired. In all cases they were rented through a Swedish temporary agency with a branch in Norway.

A total of $11 \mathrm{CDs}$ with different specialties and areas of expertise agreed to be interviewed. They were all specialists in fields such as general practice, psychiatry, anesthesia, gynecology, orthopedics, and otolaryngology. Although this was a small group of CDs, we wished to have as much of a nonhomogeneous group as possible, taking into consideration factors such as gender, the professional specialty of the doctors and experience from working through agencies at another hospital than their home hospital or clinic, meaning that they could have experience from more than one geographic area. They were chosen from a list that one of the researchers had access to from working at a TWA. Further, they were spread across large parts of Norway, from north to south (see Table $1)$.

All CDs served as consultants in Norway. They were based in a permanent appointment in a hospital, operated their own firms, or were retired. This meant that the consulting took place during their vacations, in connection with com-

Table 1. The specialization and geographic location of study participants.

\begin{tabular}{|c|c|}
\hline Consultant Doctors in total & 11 \\
\hline \multicolumn{2}{|l|}{ Gender } \\
\hline - Men & 6 \\
\hline - Women & 5 \\
\hline \multicolumn{2}{|l|}{ Age } \\
\hline$-41-50$ & 2 \\
\hline$-51-60$ & 6 \\
\hline$-\quad>61$ & 3 \\
\hline \multicolumn{2}{|l|}{ Specialization } \\
\hline - Anesthesiology & 5 \\
\hline - Psychiatry & 2 \\
\hline - General Practitioner & 1 \\
\hline - Orthopedics & 1 \\
\hline - Otorhinolaryngology & 1 \\
\hline - Obstetrics and gynecology & 1 \\
\hline \multicolumn{2}{|l|}{ Geographic location } \\
\hline Working in Norway and Sweden & 4 \\
\hline Working in Norway Solely & 1 \\
\hline Working in Norway, Sweden and Denmark & 2 \\
\hline $\begin{array}{l}\text { Working in Norway, Sweden and other European } \\
\text { countries }\end{array}$ & 4 \\
\hline
\end{tabular}


pensatory leave, or when the doctors personally felt that it suited them. Inclusion and exclusion criteria are presented in Table 2.

When the selected interviewees were asked to participate, they were sent an email with a letter giving them information on the study and its objective. It was clear that their participation was voluntary and that the data would be handled confidentially. Only one doctor did not wish to participate. When the consultant doctors had accepted to participate in the study, several asked for the questions on beforehand to be prepared and to make the interview efficient in their busy every day work life. Therefore, we chose to send the questions in advance of the interview to all the CDs. In order to test the method and the recording equipment, a pilot interview was conducted beforehand.

\subsection{Interviews}

Because the doctors were geographically spread out, we chose to perform telephone interviews. The advantage of such interviews is that the interviews can be done within a shorter period of time, and interviewees who live far away can be contacted easily.

Interviews with five females and six males working through TWAs were carried out. The interviews lasted from 25 to 70 minutes and followed a questionnaire guide with semi structured questions. The interview guide covered questions about the doctors' perception of how their competence is utilized when they work as consultants and what impact this has on their psychosocial work environment. The interviewer had a recording app on the iPhone that made it possible to record the interviews. All participants agreed to the interview being recorded and the text being transcribed.

\subsection{Analysis}

The interviews were analyzed in accordance with a content analysis method that

Table 2. The inclusion and exclusion criteria.

\section{Inclusion criteria}

- $\quad$ The doctors were specialized Medical Doctors

- The doctor had at some point in his/her carrier been working through a temporary work agency

- They worked as consultant doctors at least 2 weeks per year at another hospital/clinic than their own workplace

- They had experience from working in Norway, or Norway and Sweden, or Norway and Sweden and an additional European country

\section{Exclusion criteria}

- No medical specialty

- Worked less than two weeks/year

- Did not agree to do a telephone interview

- Did not wish for the interview to be recorded

- Did not have experience from working in Norway or Sweden 
was carried out in four steps [34]:

1) The text was read through on two different occasions. This allowed the researchers to secure all the relevant information. Open coding was used, meaning that short sentences were marked to summarize the material.

2) The sentences were compared to each other to identify repetitions. When an overall picture of the material had been created, unnecessary material and useless information were eliminated.

3) Useful sentences were sorted into different categories to be analyzed further. The sentences belonging to the different categories were put together into a text focusing on the aim of the study to answer the two research questions.

4) The data were analyzed on the basis of relevant theory (presented in the Theoretical perspectives section).

Overall, we collected data on CDs' ability to master their knowledge and skills in relation to the specific workplace norms and values, and we interpreted the results in terms of psychosocial job characteristics and health and well-being.

\subsection{Ethics}

The interviewees were sent a letter inviting them to participate in this study. In the letter, we gave information about the study, and that all the material would be treated with great confidentiality and with respect for integrity. It was also clear that the CDs were free to cancel their participation at any time. When answering the letter, they were to sign a consent letter, if they wished to participate in the study.

As the CDs were geographically located in three different countries, and there would be neither time nor economical possibilities to travel around to perform interviews with the consultants in person, the choice of performing telephone interviews was made. They were performed during private and calm surroundings in the private home of one of the authors. The names of the CDs were coded, and all the material was preserved in a locked drawer at Mid Sweden University. The material cannot be traced back to the individual CD and the material has been treated with great confidentiality.

\section{Discussion of Findings}

The analysis revealed two main categories: 1) Perception of how competence is being utilized, and 2) Perceived psychosocial work environment. Four sub-categories were determined to be essential in each category.

\subsection{Perception of How Competence Is Being Utilized}

When reflecting on whether their competence is utilized and how, the doctors' experiences of consultancy assignments can be analyzed into the following four sub-categories: 1) allowing contribution, 2) utilization of competence, 3) unglamorous assignments, and 4) indifferent attitude. 


\subsubsection{Allowing Contribution}

Consultants expressed that their competence is being utilized and that they are allowed to contribute to the hosting workplace.

You contribute with competence; you can contribute with advice and... suggestions from another place where you did it this and this way and that it works. (Interview Person 2)

This quote indicates that the CDs are able to contribute with curiosity, to view routines in a new way, and to pass on knowledge and procedures from elsewhere. One aspect of this finding is the suggestion that organizational knowledge transfer increases innovativeness and is associated with higher levels of performance [[35], p. 836]. Hence, one might suggest that the contribution of the competence of the $\mathrm{CD}$ might be of importance to the hosting hospitals.

The analysis showed that the experience of consultants is that their external perspective is normally looked upon as a positive thing. However, it is important that the consultant take a humble approach:

You can't just knock on the door and say I am used to doing it this way; it's much better than how you do it, that's not possible. But there is, at almost all workplaces, a spontaneous interest in your experiences and they ask for them. (Interview Person 11)

You can tell them about other routines that might be better where you usually work... If you do it the wrong way you will be looked upon as a "besserwisser." (Interview Person 10)

The above quotes indicate a high level of control, meaning the permanent staff will normally listen to the CDs' experience and expertise as long as the consultant has a humble approach. The permanent staff members will spontaneouslylisten to what the consultant has to say as long as they do not have consultants frequently.

I believe that you may have a very good professional exchange, if a clinic isn't totally dependent on a consultant but if they have a consultant as a supplement every now and then... As long as they're not too frequent it is a very positive medical, scientifically, and practical exchange: a vitamin injection for the clinic. (Interview Person 3)

The social climate factors may be connected to the CC's dependence on consultants to manage the everyday functioning of the organization. As long as both partners have an open mind and show mutual curiosity and respect for each other's experiences and competence, both CDs and permanent staff will be able to extend their competence. It is unfortunate, however, if this exchange is lost due to the CC being frequently dependent on external consultants.

As described in this subcategory, the interviewees experience a positive exchange of competence or have the possibility to contribute with their competence. However, one might suggest that this applies for as long as the CC does not depend on consultants frequently. When this is the situation, it seems that 
the exchange of competence is less interesting for the permanent staff members, who grow tired of receiving guest consultants.

\subsubsection{Utilization of Competence}

The consultants express that they get satisfaction from being able to help the patients and that the patients appreciate their help. In such cases they feel that their competence is utilized and that it affects their work satisfaction "to help the patients, to be appreciated, and to be able to use your competence and skills in order to make the life better for the patients." (Interview Person 5).

The quote indicates that high control is a key factor when it comes to the experience of job satisfaction, or the ability to feel that one has used one's competence to help or satisfy patients. This is in accordance with what Venkataramani, Labianca, and Grosser [29] described, as "job satisfaction has been defined as a psychological state represented by cognitive and affective indicators resulting from the evaluation of one's job experiences" (p. 1031).

Many consultants have been experienced specialists for years. Since consultants are able to cover many shifts, their competence and expertise are often utilized to a great extent. Meeting an experienced expert instead of a doctor in training can make a big difference for the patient and the organization as a whole:

The competence among the consultants that are on primary call is quite high, compared to the doctors that are still training... I think that is a good point. We increase the average age among the ones being on primary call, but also the level of experience and competence. I think this is good for the patient security as well... I think this is something that is mentioned too little in the debates. If you have a specialist with 20 years of experience, or a doctor under training at the primary call, it makes a big difference. (Interview Person 11)

Here we can see that the care and hence the safety of the patient may actually be higher when he or she meets with a $\mathrm{CD}$ with greater competence and experience than a doctor who belongs to the permanent staff but is still in training.

This subcategory implies that the experience of CDs allows them to raise the existing level of competence at a CC. Due to their level of competence, this may lead to a feeling of job satisfaction in terms of high control over the job situation when they are able to contribute in a positive way.

\subsubsection{Unglamorous Assignments}

Although most of the interviewees had had positive experiences of being heard and contributing their competence, some of the doctors did not share these experiences.

You often get quite unglamorous assignments... take the patients and problems that noone else wants. (Interview Person 8)

The CDs expressed that permanent staff members take on the more interest- 
ing cases. Håkansson and Isidorsson [5] revealed in their research discussing TWAs in general that the consultants in some cases are integrated and perform the same, but they have to do simpler work tasks than the permanent staff.

We're being used for routine work and simple but boring work assignments. (Interview Person 9)

The analysis showed that some doctors experience a low level of control; they are seen solely as part of the workforce and are at the CC only to solve day-today assignments and to take care of concrete needs.

You have to deal with worse conditions to be able to do a good job. They don't invest in quality but in number of patients. They want to fix a waiting list. (Interview Person 2)

Some consultants may be employed to perform the routine work without being expected to care about the surrounding organizational circumstances. Such experiences of low control and work with low demands may be demotivating. According to Edvardsson, Larsson, and Setterlind [28], "knowledge and experience alone without motivation and enthusiasm have proved to be insufficient for good performance" (p. 254). Having a feeling of being looked upon solely as part of the workforce and not as a person with a significant competence may be a negative experience, as the feeling of contributing one's competence is not significant in such a situation.

At some places... it is very clear. The boss said that we pay a lot of money to have you here, that wasn't nice, you shall work and do what we say. I see a tendency that "now we're buying manpower" and you are looked upon as workforce, just an order that has been placed. (Interview Person 2)

The quote indicates that the CC does not always see the person behind the doctor; an order may be sent out to the TWAs advertising a need for a doctor with a certain expertise. Hence, in such situations, the CDs encounter weak social support in terms of the impersonal attitude of the CC's leaders, and they may therefore offer an impersonal contribution to the workplace.

The analysis showed that the interviewees believed that the medical profession has been subject to negative changes in the last few years, with more focus given to administration over the treatment of patients.

You are an overqualified slave; that's how it has become for doctors. (Interview Person 10)

Some doctors felt like they were performing unglamorous assignments that were not a natural part of why they chose to become a doctor. To be told that one is looked upon as something that has been paid for, almost as a tool in a toolbox, does not provide motivation to contribute. This suggests the presence of a combination of low control, low demands, and weak social support.

This subcategory implies that some consultants get unglamorous assignments when consulting. Thus, the consultant is looked upon as part of the manpower meant solely to shorten a waiting list and perform routine work. 


\subsubsection{Indifferent Attitude}

The aspect of having an indifferent attitude regarding whether one's competence as a $\mathrm{CD}$ is utilized will be further presented in the following section.

The need decides. If there's no need to use all the competence... well then there's not. (Interview Person 1)

It seems to be the need for the CC that guides how the competence of the consultant is utilized. Surely it is logical that if the hospital does not perform anesthesia on small babies, for example, the need for this competence will not be an issue, and the anesthesiologist consultant will perform other assignments even if he or she is an expert in the subject.

The analysis showed that despite feelings of not always contributing with competence or expertise, the CDs accept this as part of the package while experiencing other advantages when working as consultants:

Your competence isn't always utilized to the maximum. You can be the most experienced, but you will not get these assignments because someone is training. (Interview Person 5)

The above quote indicates that even if the $\mathrm{CD}$ is the most experienced doctor onsite, he or she still may not get the chance to contribute his or her competence, but this kind of low control is not always troubling.

You can't expect that much, because you're a guest and you've made a deal. So you earn money and then you leave. (Interview Person 6)

The analysis showed that some consultants actually experience it as a positive thing not always having to perform at their level of competence when working as a consultant.

I believe that most consultants will hit a lower level of competence when they are out than they normally have... Most people probably find that to be a relief. (Interview Person 10)

This subcategory reveals that some consultants find it positive to be able to perform at a lower level of control and demand while working on a consultancy assignment, hence the experience is often that it is perfectly fine to do routine work and not use one's whole capacity or competence.

\subsection{Perceived Psychosocial Work Environment}

The doctors' experiences of and opinions about the utilization of their competence and what impact it has on their perceived psychosocial work environment when working on consultancy assignments can be analyzed in four subcategories: 1) demands on their competence, 2) alienation, 3) lack of planning, and 4) the hosting hospital's involvement.

\subsubsection{Demands on the Competence}

The analyses showed that higher demands are placed on the competence of the $\mathrm{CD}$ when compared to the permanent staff. 
You are being looked upon with a magnifying glass in all you do. It means that people place higher demands on the consultant doctor; you have to be really good to get accepted. (Interview Person 7)

If the $\mathrm{CC}$ feels the need to exercise control while also expecting more from the consultant, this might have a stressful and negative impact on the CD.

This subcategory implies that some CDs face high demands and have low control over the work situation.

\subsubsection{Alienation}

The analyses showed that the consultants do not experience being a part of the work environment of the $\mathrm{CC}$ and that they are not likely to be integrated into the psychosocial work environment.

That's a thing that's a bit sad being a consultant doctor; at some [workplaces] you're not included, you know that you're not welcomed to meetings about information and work environment, you're just there to meet the patients... The rest of the staff gather once a week, but I'm seeing patients. (Interview Person 2)

The above quote indicates that, relative to permanent staff, some consultants feel excluded by or experience weak social support from the CC organization. According to Venkataramani, Labianca, and Grosser [29], "individuals have a strong need to feel included and respected by others around them" (p. 1031).

If the CC suffers from a non-including work environment, this will naturally affect the hired consultant in terms of not being welcomed into the organization and his or her ability to take part in the psychosocial work environment.

In the primary care the work environment is horrible, there are doctors that won't even leave the room, they bring in coffee and a sandwich for lunch because the workload is so heavy... It's horrible. (Interview Person 5)

This indicates the unpredictability of demands that the CD can expect upon arriving for the first time at a CC. One can suggest that this experience, as part of the everyday working life, will have a negative impact on the consultant because a poor psychosocial work environment, as well as uncertainty, creates mental stress. According to Bogue, Guarneri, Reed, Bradley, and Hughes [36], "physician stress can lead to career dissatisfaction, disruptive behavior, burnout and career exit, substance abuse, health concerns, personal and family problems, and in the worst cases suicide" (p. 32).

Some CDs experience positive aspects of not being integrated or involved in the CC's psychosocial work environment, however.

If the work environment is negative you can stay outside it. You can notice if it is, it does not affect you, but if it would start to affect you you can just clarify that that's a place you'll never return to again. (Interview Person 3)

Here we can see that doctors who are working on a consultancy assignment at a CC with a negative work environment have the freedom not to get involved or 
become influenced.

You are in a situation like marriage with your workplace. A consultant has a more casual relation where he performs his assignments and then leaves again; it can never be the same relation regarding the work environment, as it will for the ordinary staff. (Interview Person 6)

Whereas a permanent employee risks becoming stuck in a negative psychosocial work environment, the consultant is not bound to one place.

This subcategory, as related by the interviewees, involves both negative and positive aspects of being regarded as an outsider at the CC. The analysis shows that CDs' experience of low social support is positive when it allows them not to be attached to a negative psychosocial work environment and to stand outside conflicts, but it is negative when it causes mental stress and uncertainty.

\subsubsection{Lack of Planning}

The analysis showed that if the CC has not prepared assignments or planned work for the consultant, this can contribute to a feeling of being excluded.

Many times they have not made good plans or no plans at all in relation to the person who's coming. (IP6)

The CDs indicated dissatisfaction due to bad planning or lack of any planning before the consultant's arrival. This kind of low control might lead to negative feelings for the consultant due to his or her having been thrown into a role to fill a need without the underlying plans for his or her work being laid. Without clear directives, it may be a challenging experience to contribute competence in a natural way.

If you go one week here and one week there, you need a certain mental strength. (IP10)

This quote indicates that one needs mental strength in order to deal with an ever-changing psychosocial work environment. The analysis showed that the doctors sometimes feel they miss a level of depth or meaningfulness in the working tasks they are given as consultants.

The subcategory suggests that working as a CD might be a stressful way of performing the profession due to the ever-changing workplace, the expectation of operating independently without putting an extra burden on permanent staff, and the necessity of performing tasks one is not comfortable with or tasks one has not been properly introduced to.

\subsubsection{The Client Companies' Involvement}

The analyses revealed a differentiated picture regarding CDs' experiences of interacting with permanent staff and the psychosocial work environment.

You have your darling places, here you hang out in coffee rooms and after work hours... It's hard to explain why some places are good and some bad. One to two people can poison the work environment. (Interview Person 10) 
The above quote suggests that there is a difference, depending on the hospital and individuals working at the hospitals, when it comes to being welcomed into the psychosocial work environment and the social culture of the permanent staff. Venkataramani, Labianca, and Grosser [29] stated, "people generally expect their interactions and relationships with coworkers to be polite, friendly or neutral and not to be negative or antagonistic" (p. 1030). However, when this is not the case, it may contribute to a feeling of uncertainty around what can be expected of the work environment.

It is different: If you lease someone due to temporary illness it is good, but if it is because of chronic lack of staff and work demands and a bad work environment you will not be welcomed with open arms. (Interview Person 4)

How the consultant will be included in the psychosocial work environment depends on the specific need of the CC and the frequency of this need. If the hospital itself suffers from a negative work environment and frequent lack of permanent staff, the permanent staff might be tired of working with temporary consultants.

There is such a variation between the hospitals... but some are less positive, you shall just shut your mouth and do the job. (Interview Person 4)

In some hospitals, the consultant is treated in a solely functional and impersonal way. Hence, the competence of the doctor is interpreted at a strictly professional or educational level, while the person behind the competence is of little importance [37]. This kind of weak social support seems to be perceived in a negative way by consultants.

The quote also seems to suggest that the consultants have to keep their ideas and thoughts about the job tasks to themselves without questioning. This may lead to feelings of discomfort in terms of "negative moods, emotions and other adverse outcomes such as social ostracism, hindrance and undermining" [[29], p. 1031].

The involvement of the consultant and how he or she interprets the psychosocial work environment, as discussed, seems to vary. Some consultants also stated that they are part of a psychosocial work environment that is creative and mutually developing.

It depends on the policies within the hospital, ... how the [hospital and the] ward creates a work environment. (Interview Person 1)

This quote suggests that sometimes the CC is involved and cares about the actual person, the consultant, but it depends on the policies and the tradition of creating a positive psychosocial work environment within the CC.

This subcategory relates to the different aspects of the CCs' involvement in the work of the CDs. As discussed earlier, some of the interviewees found not being integrated in the psychosocial work environment of the $\mathrm{CC}$ a positive factor. However, as discussed in this section, the majority argued that it is of great importance to be welcomed into a positive work environment with friendly col- 
leagues and to experience strong social support.

\section{Discussion and Conclusions}

The purpose of this pilot study was to explore how CDs experience their competence as utilized in practice and what impact this has on their perceived psychosocial work environment. As such a large number of doctors now work as consultants, the findings of the study are important, demonstrating how consultants respond to the conditions they encounter while working at different hospitals or clinics and how they try to make sense of their experiences and give meaning to their worlds. The findings in this article are based on a small group of doctors who specialize in different fields; hence, they represent different specialties within the medical field. It was also a conscious choice to create an equal distribution between the genders by interviewing six men and five women.

The analysis, as summarized in Table 3, uncovers a picture of a quite differentiated view, and it is possible to draw two main conclusions from our results.

The first conclusion is that most of the consultants experience that their competence is only utilized to a certain extent, which weakens their work satisfaction and feeling of playing a more or less active role in the psychosocial work environment. Being a CD on consultancy assignments entails high work demands, low control over one's work situation, and weak support. In earlier research, this is associated with a worse job situation when it comes to employee health and well-being [e.g., [30] [31]]. However, there are CDs who accept being treated by means of an impersonal approach and perceive this as a relief because it means they are not required to deal with complex tasks or engage with the organization in general. Meanwhile, there are CDs who dislike this aspect of their work. This implies that the TWAs, bearing in mind psychosocial considerations, should choose the right persons to work as a hired consultant and should ensure that the person is aware of the fact that his or her involvement in the client company will probably be limited to routine tasks.

The second conclusion is that CDs experience workplaces as different: some are welcoming and others are not. This difference may be due to the reasons for renting personnel. A temporary absence in the client company is associated with a welcoming working climate, whereas chronic understaffing is linked to a more dismissive working climate. A dismissive climate inhibits the $\mathrm{CD}$ and his or her use of competencies. Therefore, CDs risk their competencies being underused because their main focus is on their concrete tasks, whereas they should ignore the tasks' organizational context. In this psychosocial environment, the $\mathrm{CD}$ must be prepared to feel like an outsider [38]; this partly includes managing his or her perceptions of low control, high demands, and weak social support, which may be stressful, according to Jönsson [9].

The implication of the second main conclusion is that CDs feel supervised and perceive themselves as cut off from the wider organizational context. A further complication may be the importance of the $\mathrm{CD}$ keeping quiet about his or her insights into the inadequate organization of the CC. Overall, this implies that a 
Table 3. Main categories and sub-categories, and summary of findings.

\begin{tabular}{|c|c|c|c|}
\hline $\begin{array}{c}\text { Main } \\
\text { categories }\end{array}$ & Sub-categories & Utterances & Summary of findings \\
\hline \multirow{4}{*}{$\begin{array}{l}\text { Perception of } \\
\text { how } \\
\text { competence } \\
\text { is being } \\
\text { utilized }\end{array}$} & $\begin{array}{l}\text { Allowing } \\
\text { contribution }\end{array}$ & 4 & $\begin{array}{l}\text { The interviewees experience a positive exchange of } \\
\text { competence for as long as the CC does not depend } \\
\text { on consultants frequently. }\end{array}$ \\
\hline & $\begin{array}{l}\text { Utilization of } \\
\text { competence }\end{array}$ & 2 & $\begin{array}{l}\text { May lead to a feeling of job satisfaction in terms of } \\
\text { high control over the job situation. }\end{array}$ \\
\hline & $\begin{array}{l}\text { Unglamorous } \\
\text { assignments }\end{array}$ & 5 & $\begin{array}{l}\text { Performing unglamorous assignments suggests the } \\
\text { presence of a combination of low control, } \\
\text { low demands, and weak social support. }\end{array}$ \\
\hline & Indifferent attitude & 4 & $\begin{array}{l}\text { Some consultants find it positive to be able to perform } \\
\text { at a lower level of control and demand while } \\
\text { working on a consultancy assignment. }\end{array}$ \\
\hline \multirow{4}{*}{$\begin{array}{l}\text { Perceived } \\
\text { psychosocial } \\
\text { work } \\
\text { environment }\end{array}$} & $\begin{array}{l}\text { Demands on the } \\
\text { competence }\end{array}$ & 2 & $\begin{array}{l}\text { Implies that some CDs face high demands and } \\
\text { have low control over the work situation. }\end{array}$ \\
\hline & Alienation & 4 & $\begin{array}{l}\text { Experience of low social support is positive when it allows CDs not to be } \\
\text { attached to a negative psychosocial work } \\
\text { environment and to stand outside conflicts, but negative when it causes } \\
\text { mental stress and uncertainty. }\end{array}$ \\
\hline & Lack of planning & 2 & $\begin{array}{l}\text { Working as a CD might be a stressful due to the } \\
\text { ever-changing workplace, the expectation of operating } \\
\text { independently without putting an extra burden on } \\
\text { permanent staff, and the necessity of performing tasks } \\
\text { one is not comfortable with or tasks one has not } \\
\text { been properly introduced to. }\end{array}$ \\
\hline & $\begin{array}{l}\text { The client } \\
\text { companies' } \\
\text { involvement }\end{array}$ & 4 & $\begin{array}{l}\text { The majority of the CDs argued that it is of great } \\
\text { importance to be welcomed into a positive work } \\
\text { environment with friendly colleagues and to } \\
\text { experience strong social support. }\end{array}$ \\
\hline
\end{tabular}

welcoming attitude toward CDs' practical contribution to the CC's activities leads to their appreciating the psychosocial environment, while an unsympathetic or a conditional approach forces CDs to choose to limit their involvement in the CC.

To draw conclusions that will be exclusively valid for one specific specialty within the medical field, further research on a larger group of doctors within that specialty would be of interest.

\section{Acknowledgements}

The participants are acknowledged for their willingness to take part in the pro- 
ject.

\section{Conflict of Interest}

There are no conflicts of interest among the authors.

\section{References}

[1] Augustsson, G. (2014) Temporary and Regular Workers Fulfill Their Tasks Side-bySide, but in Different Learning Conditions. Journal of Workplace Learning, 26, 7990. https://doi.org/10.1108/JWL-06-2013-0037

[2] Augustsson, G. (2016) The Client Company Marginally Utilises the Knowledge of Highly Skilled Temporary Staff. Journal of Education and Work, 29, 519-539.

https://doi.org/10.1080/13639080.2014.997681

[3] Domanders, E., Engcrantz, S. and Lindley-Nord, M. (2013) Hyrläkare räddar sjukvården [Consultant Doctors Rescues Healthcare]. Dagens samhälle, Debatt. http://www.dagenssamhalle.se/debatt/hyrlaekare-raeddar-sjukvarden-5260

[4] Håkansson, K., Isidorsson, T. and Strauss-Raats, P. (2013) Kunskapssammanställning: Arbetsmiljö för hyresarbetskraft: Inhyrdas fysiska och psykosociala arbetsmiljö [Knowledge Compilation, Work for Rented Personnel-Rented's Physical and Psychosocial Work Environment]. Arbetsmiljöverket, Stockholm.

[5] Håkansson, K. and Isidorsson, T. (2012) Work Organizational Outcomes of the Use of Temporary Agency Workers. Organization Studies, 33, 487-505. https://doi.org/10.1177/0170840612443456

[6] Foss, N.J. and Knudsen, C., Eds. (1996) Towards a Competence Theory of the Firm. Routledge, London.

[7] Karlson, N. and Fergin, E. (2013) Vad är kompetens? [What Is Competence?] Rapport nr 6, RATIO, Stockholm.

http://ratio.se/media/212607/vad_\%C3\%A4r_kompetens__rapport_nr_6.pdf

[8] Karlsson, M.L., Björklund, C. and Jensen, I. (2012) The Relationship between Psychosocial Work Factors, Employee Health and Organizational Production-A Systematic Review. IFAU, Institute for Evaluation of Labour Market and Education Policy, Working Paper.

http://www.ifau.se/Upload/pdf/se/2012/wp12-08-The-relationship-between-psycho social-work-factors-employee-health-and-organisational-production.pdf

[9] Jönsson, S. (2012) Psychosocial Work Environment and Prediction of Job Satisfaction among Swedish Registered Nurses and Physicians-A Follow up Study. Scandinavian Journal of Caring Sciences, 26, 236-244. https://doi.org/10.1111/j.1471-6712.2011.00924.x

[10] Michie, S. and Williams, S. (2003) Reducing Work Related Psychosocial Ill Health and Sickness Absence: A Systematic Literature Review. Occupational and Environmental Medicine, 60, 3-9. https://doi.org/10.1136/oem.60.1.3

[11] Standing, G. (2013) Prekariatet. Den nya farliga klassen [The Precariat. The New Dangerous Class]. Daidalos, Göteborg.

[12] Mechanic, D. (2003) Physician Discontent, Challenges and Opportunities. JAMA, 290, 941-946. https://doi.org/10.1001/jama.290.7.941

[13] Säljö, R. (2000) Lärande i praktiken: Ett sociokulturellt perspektiv [Learning in Practice: A Socio-Cultural Perspective]. Norstedts, Stockholm.

[14] Currie, G. and White, L. (2012) Inter-Professional Barriers and Knowledge Brokering in an Organizational Context: The Case of Healthcare. Organization Studies, 33, 
1333-1361. https://doi.org/10.1177/0170840612457617

[15] Beckett, D. and Hager, P. (2000) Making Judgments as the Basis for Workplace Learning: Towards an Epistemology of Practice. International Journal of Lifelong Education, 19, 300-311.

[16] Ellström, P.-E. and Kock, H. (2009) Competence Development in the Workplace. Concepts, Strategies and Effects. In: Illeris, K., Ed., International Perspectives on Competence Development. Developing Skills and Capabilities, Routledge, London, 34-54.

[17] Ellström, P.-E. (1992) Kompetens, utbildning och lärande i arbetslivet: Problem, begrepp och teoretiska perspektiv [Competence, Training and Learning at Work: Problems, Concepts, and Theoretical Perspectives]. Publica, Stockholm.

[18] Ellström, P.-E. (1997) The Many Meanings of Occupational Competence and Qualification. Journal of European Industrial Training, 21, 266-273. https://doi.org/10.1108/03090599710171567

[19] Gherardi, S. and Nicolini, D. (2000) To Transfer Is to Transform: The Circulation of Safety Knowledge. Organization, 7, 329-348. https://doi.org/10.1177/135050840072008

[20] Sandberg, J. (2000) Understanding Human Competence: An Interpretative Approach. Academy of Management Journal, 43, 9-25. https://doi.org/10.2307/1556383

[21] Wenger, E. (1998) Communities of Practice: Learning, Meaning, and Identity. Cambridge University Press, Cambridge. https://doi.org/10.1017/CBO9780511803932

[22] Billett, S. (2004) Co-Participation at Work: Learning through Work and throughout Working Lives. Studies in the Education of Adults, 36, 190-205. https://doi.org/10.1080/02660830.2004.11661496

[23] Billett, S. (2008) Learning through Work: Exploring Instances of Relational Interdependencies. International Journal of Educational Research, 47, 232-240. https://doi.org/10.1016/j.ijer.2008.07.006

[24] Brown, J.S. and Duguid, P. (1991) Organizational Learning and Communitiesof-Practice: Toward a Unified View of Working, Learning, and Innovation. Organization Science, 2, 40-57. https://doi.org/10.1287/orsc.2.1.40

[25] Aronsson, G., Hellgren, J., Isaksson, K., Johansson, G., Sverke, M. and Torbiörn, I. (2012) Arbets-och organisationspsykologi: Individ och organisation i samspel [Work and Organizational Psychology: Individual and Organization in Interaction]. Natur and Kultur, Stockholm.

[26] Johnson, J.V. and Hall, E.M. (1988) Job Strain, Work Place Social Support, and Cardiovascular Disease: A Cross-Sectional Study of a Random Sample of the Swedish Working Population. American Journal of Public Health, 78, 1336-1342. https://doi.org/10.2105/AJPH.78.10.1336

[27] Karasek, R. and Theorell, T. (1990) Healthy Work: Job Stress, Productivity and the Reconstruction of Working Life. Basic Books, New York.

[28] Edvardsson, B., Larsson, G. and Setterlind, S. (1997) Internal Service Quality and the Psychosocial Work Environment: An Empirical Analysis of Conceptual Interrelatedness. The Service Industries Journal, 17, 252-263. https://doi.org/10.1080/02642069700000014

[29] Venkataramani, V., Labianca, G. and Grosser, T. (2013) Positive and Negative Workplace Relationships, Social Satisfaction, and Organizational Attachment. Journal of Applied Psychology, 98, 1028-1039. https://doi.org/10.1037/a0034090 
[30] Kivimäki, M., Vahtera, J., Elovainio, M., Keltikangas-Järvinen, L., Virtanen, M., Hintsanen, M., Väänänen, A., Singh-Manoux, A. and Ferrie, J.E. (2008) What Are the Next Steps for Research on Work Stress and Coronary Heart Disease? Scandinavian Journal of Work, Environment and Health Supplement, 6, 33-40.

[31] Eller, N.H., Netterstrøm, B., Gyntelberg, F., Kristensen, T.S., Nielsen, F., Steptoe, A. and Theorell, T. (2009) Work-Related Psychosocial Factors and the Development of Ischemic Heart Disease: A Systematic Review. Cardiology in Review, 17, 83-97.

https://doi.org/10.1097/CRD.0b013e318198c8e9

[32] De Lange, A.H., Taris, T.W., Kompier, M.A.J., Houtman, I.L.D. and Bongers, P.M. (2003) The Very Best of the Millennium: Longitudinal Research and the DemandControl-(Support) Model. Journal of Occupational Health Psychology, 8, 282-305. https://doi.org/10.1037/1076-8998.8.4.282

[33] Bowe, B. and Sloan, A. (2014) Phenomenology and Hermeneutic Phenomenology: The Philosophy, the Methodologies, and Using Hermeneutic Phenomenology to Investigate Lecturers' Experiences of Curriculum Design. Quality and Quantity, 48, 1291-1303. https://doi.org/10.1007/s11135-013-9835-3

[34] Burnard, P. (1996) Teaching the Analysis of Textual Data: An Experiental Approach. Nurse Education Today, 16, 278-281. https://doi.org/10.1016/S0260-6917(96)80115-8

[35] Van Wiijk, R., Jansen, J.J.P. and Lyles, M.A. (2008) Inter- and Intra-Organizational Knowledge Transfer: A Meta-Analytic Review and Assessment of Its Antecedents and Consequences. Journal of Management Studies, 45, 830-853. https://doi.org/10.1111/j.1467-6486.2008.00771.x

[36] Bogue, R.J., Guarneri, J.G., Reed, M., Bradley, K. and Hughes, J. (2006) Secrets of Physician Satisfaction. Study Identifies Pressure Points and Reveals Life Practices of Highly Satisfied Doctors. The Physician Executive, 32, 30-38.

[37] Augustsson, G. (2012) The Organizational Control of Temporary Workers: An Interview Study in Sweden. International Journal of Management, 29, 48-63.

[38] Elias, N. and Scotson, J.L. (1994) The Established and the Outsiders: A Sociological Enquiry into Community Problems. 2nd Edition, Sage, London.

\section{Submit or recommend next manuscript to SCIRP and we will provide best service for you:}

Accepting pre-submission inquiries through Email, Facebook, LinkedIn, Twitter, etc. A wide selection of journals (inclusive of 9 subjects, more than 200 journals)

Providing 24-hour high-quality service

User-friendly online submission system

Fair and swift peer-review system

Efficient typesetting and proofreading procedure

Display of the result of downloads and visits, as well as the number of cited articles

Maximum dissemination of your research work

Submit your manuscript at: http://papersubmission.scirp.org/

Or contact health@scirp.org 